\title{
Antimicrobial and anti-Quorum Sensing activities of selected medicinal plants of Ethiopia: Implication for development of potent antimicrobial agents
}

Ketema Bacha ${ }^{1 *}$, Yinebeb Tariku², Fisseha Gebreyesus ${ }^{3}$, Shibru Zerihun ${ }^{4}$, Ali Mohammed ${ }^{5}$, Nancy Weiland-Bräuer ${ }^{6}$, Ruth A. Schmitz ${ }^{6}$ and Mulugeta Mulat ${ }^{1,7}$

\begin{abstract}
Background: Traditional medicinal plants have been used as an alternative medicine in many parts of the world, including Ethiopia. There are many documented scientific reports on antimicrobial activities of the same. To our knowledge, however, there is no report on the anti-Quorum Sensing (Quorum Quenching, QQ) potential of traditional Ethiopian medicinal plants. As many of the opportunistic pathogenic bacteria depend on Quorum Sensing (QS) systems to coordinate their virulence expression, interference with QS could be a novel approach to control bacterial infections. Thus, the aim of this study was to evaluate selected medicinal plants from Ethiopia for their antimicrobial activities against bacterial and fungal pathogens; and to assess the interference of these plant extracts with QS of bacteria.

Methods: Antimicrobial activities of plant extracts (oil, resins and crude extracts) were evaluated following standard agar diffusion technique. The minimum inhibitory concentrations (MIC) of potent extracts were determined using 96 well micro-titer plates and optical densities were measured using an ELISA Microplate reader. Interference with Quorum Sensing activities of extracts was determined using the recently established E. coli based reporter strain Al1-QQ.1 and signaling molecule N-(B-ketocaproyl)-L-homoserine lactone (3-oxo-C6-HSL).

Results: Petroleum ether extract of seed of Nigella sativa exhibited the highest activity against both the laboratory isolated Bacillus cereus [inhibition zone (IZ), $44 \pm 0.31 \mathrm{~mm}$ ] and B. cereus ATCC 10987 (IZ, $40 \pm 2.33 \mathrm{~mm}$ ). Similarly, oil extract from mature ripe fruit husk of Aframomum corrorima and mature unripe fruit of $A$. corrorima revealed promising activities against Candida albicans ATCC 90028 (IZ, $35 \pm 1.52 \mathrm{~mm}$ ) and Staphylococcus aureus DSM 346 (IZ, $25 \pm 1.32 \mathrm{~mm}$ ), respectively. Antimicrobial activities of oil extract from husk of A. corrorima and petroleum ether extract of seed of $\mathrm{N}$. sativa were significantly higher than that of the control antibiotic [Gentamycin sulfate, (IZ, 25-30 mm)]. The lowest MIC value $(12.5 \mathrm{mg} / \mathrm{mL})$ was recorded for oil from husk of $A$. corrorima against Pseudomonas aeruginosa. Of the total eighteen extracts evaluated, two of the extracts [Methanol extract of root of Albiza schimperiana (ASRM) and petroleum ether extract of seed of Justica schimperiana (JSSP)] interfered with cell-cell communication most likely by interacting with the signaling molecules.

(Continued on next page)
\end{abstract}

\footnotetext{
* Correspondence: ketemabacha2002@yahoo.com

1 Depatment of Biology, College of Natural Sciences, Jimma University,

Jimma, Ethiopia

Full list of author information is available at the end of the article
} 


\begin{abstract}
(Continued from previous page)
Conclusion: Traditional medicinal plants from Ethiopia are potential source of alternative medicine for the local community and scientific research in search for alternative drugs to halt challenges associated with the emerging antimicrobial resistance. Furthermore, the Quorum Quenching activities observed in two of the plant extracts calls for more comprehensive evaluation of medicinal plants for the control of many bacterial processes and phenotypic behaviors such as pathogenicity, swarming, and biofilm formation. Being the first assessment of its kind on the potential application of Ethiopian traditional medicinal plants for interference in microbial cell-cell communication (anti-Quorum Sensing activities), the detailed chemistry of the active compounds and possible mechanism(s) of actions of the bio-molecules responsible for the observed interference were not addressed in the current study. Thus, further evaluation for the nature of those active compounds (bio-molecules) and detailed mechanism(s) of their interaction with microbial processes are recommended.
\end{abstract}

Keywords: Alternative medicine, Drug resistance, Ethiopia, Medicinal plants, MIC, Quorum Sensing, Quorum Quenching

\section{Background}

Traditional medicinal plants have indefinite therapeutic value worldwide. The World Health Organization estimates that up to $80 \%$ of the world population still relies on traditional remedies [1] with more than 35,000 plant species being used for medication purpose in various human cultures [2]. Ethiopia is the origin and center of biodiversity for many plant species and is one of the six plant biodiversity-rich countries of Africa, being home for about 6,500 species of higher plants, $12 \%$ of which are endemic to the country $[3,4]$. Due to its long history of practice and safety, traditional medicine has become an integral part of the Ethiopian culture. Accordingly, about $80 \%$ of human population and $90 \%$ of livestock rely on traditional medicine for treatment of diseases [5]. The emergence of antibiotic resistant microbial strains and increasing failure of the available chemotherapeutics made the search for microbiologically active medicinal plants a necessity [6].

In host parasite interaction, pathogenic bacteria generally deploy two major strategies: invading host tissues (invasiveness), and producing toxins (Toxigenesis) [7, 8]. Invasiveness encompasses mechanisms for colonization (adherence and initial multiplication), ability to bypass or overcome host defense mechanisms, and the production of extracellular substances which facilitate invasion [8]. In toxigenesis, however, bacteria produce the cell associated Endotoxins or Exotoxins. Plant extracts with potential antibacterial activity interfere with one or more of the above bacterial pathogenicity strategies.

In addition to inhibition of microbial growth, natural products might also play a significant role in interfering microbial cell-cell communication processes, commonly called Quorum Sensing (QS) [9]. QS allows the perception of population density by small signaling molecules, called auto-inducers, and modifies gene expression in response to the population density $[10,11]$. It controls a wide spectrum of processes and phenotypic behaviors, including stress resistance, production of toxins and secondary metabolites, pathogenicity, swarming, and biofilm formation [11, 12]. Unlike humans and mammals that possess immune systems to defend against invaders, plants are lacking such sophisticated immunity to ward off invading pathogens. Thus, instead of relying on cellular and biochemical defense systems, plants may have evolved alternative defense mechanisms, including production of anti-QS compounds, which can be used to defeat QS pathogens [9]. According to González and Keshavan [13], eukaryotes have evolved efficiently to manipulate bacterial QS systems and protect themselves from attacks by pathogens. For instance, interference with QS systems were clearly observed among marine red alga [14], human keratinocytes [15], and human airway epithelial cells [16].

Although numerous studies have been undertaken, and have revealed the antimicrobial potential of traditional medicinal plants being used in various parts of Ethiopia [17-23], the effects of those plant extracts on bacterial cell-cell communication were not evaluated so far. Many bacteria are thought to utilize chemical signaling systems to control cellular behaviors in response to local bacterial population density for effective colonization and manipulation of host organisms, such as in disease and symbiosis [12]. Jamming such bacterial communication systems has, therefore, become an attractive target for intervention strategies to mitigate and treat infectious diseases. Gramnegative bacteria use acylated homoserine lactones as auto-inducers, while Gram-positive bacteria use oligopeptides to communicate. Report on quorum sensing and quorum sensing molecules from fungi are rare [24-26]. Two molecules have been described from the human commensal and pathogenic fungus Candida albicans, namely farnesol and tyrosol [24, 25]. The human opportunistic yeast, Cryptococcus neoformans was also reported to produce peptide type signaling molecules [26].

Irrespective of the inducer molecules used, if bacteria use the QS circuit for such diverse arrays of activities, 
identification of molecules that interfere with the inducer molecules or its expression could have paramount importance particularly in the control of microbial diseases. Thus, this study was designed to evaluate the antimicrobial activities of selected traditional medicinal plants widely used in Ethiopia, and additionally to assess effects of extracts of the plants on cell-cell signaling. The findings of the current study could pave the way for further detailed study on traditional medicinal plant resources of Ethiopia for wider application in food and pharmaceutical industries.

\section{Methods}

\section{Plant collection}

Traditional medicinal plants were collected from two districts of Jimma Zone (Kersa and Omo Nada) and also purchased from open markets of Serbo, Assendabo, and Jimma towns, Southwest Ethiopia. The collected traditional medicinal plants were labeled with their date of collection, location, medicinal uses and approximate dosages of administration based on the information gathered from the local healers (informants). The taxonomic categories of the plants were identified assisted by professional taxonomist at Jimma University; Department of Biology and Voucher specimens were deposited at Jimma University Herbarium.

\section{Preparation of plant extracts}

A total of 18 plant extracts were prepared following standard methods of plant preparation for extraction as described earlier [27]. Briefly, the collected plant specimens were properly cleaned and air dried under shade on wire mesh bed for 15 days and finally powdered manually to suitable size with metal mortar and pestle. The finger rhizomes and main rhizomes of Curcuma longa were precooked at $80{ }^{\circ} \mathrm{C}$ for $75 \mathrm{~min}$ and at $90{ }^{\circ} \mathrm{C}$ for $75 \mathrm{~min}$, respectively, to facilitate the extraction process. The powdered plant materials were subsequently extracted successively with petroleum ether, chloroform, methanol and water (the details are as given below).

\section{Isolation of volatile oil}

Volatile constituents of the study plants (Curcuma longa, Aframomum corrorima and Nigella sativa) were obtained by hydro-distillation [28] using 60-100 g samples on a glass type Clevenger apparatus for 3-4 $\mathrm{h}$ after the mixture started boiling. The crude oil was then separated and the remaining moisture content was absorbed by adding anhydrous sodium sulphate. The oil was placed in a glass vial sealed with parafilm and kept in a refrigerator $\left(2-4{ }^{\circ} \mathrm{C}\right)$ protected from direct light.

\section{Isolation of Oleo resins and crude extracts}

Oleo resins and crude extracts of the study plants (Curcuma long, Aframomum corrorima, Albiza schimperiana,
Justica schimperiana, Erythrinia brucei, Vernonia amygdalina, Nigella sativa and Ocimum sauve) were obtained by Soxhlet extraction [28] of $100 \mathrm{~g}$ samples in $1.5 \mathrm{~L}$ of the required solvents (petroleum ether, methanol, or chloroform) for $6 \mathrm{~h}$. Residual solvents were evaporated using a rotary evaporator at $40^{\circ} \mathrm{C}$. The concentrated extracts were placed in glass vials, sealed with parafilm and kept in a refrigerator $\left(2-4{ }^{\circ} \mathrm{C}\right)$ protected from direct light.

\section{Culture media and test strains}

Muller Hinton agar (MHA) and Potato Dextrose agar (PDA) were used for antimicrobial activity tests, while LB (Luria Bertani) top agar was used for Quorum Quenching assay. A total of five bacterial strains [Esherichia coli K12, DSM 498; Pseudomonas aeruginosa, DSM 1117; Staphylococcus aureus, DSM 346; Bacillus cereus ATCC 10987; B. cereus (lab isolate)] and Candida albicans ATCC 90028 were used to evaluate the antimicrobial activities of plant extracts. Besides representing bacteria of Gram positive and Gram negative categories, these bacterial strains are among the ecologically rich (Pseudomonas aeruginosa, Bacillus), hence potential contaminants, and common inhabitants of human body including skin (S. aureus) and Gastro Intestinal Tract (E. coli). Candida albicans are opportunistic fungal pathogens of public health importance especially in immune-compromised individuals. Initiation of pathogenicity processes in some of these bacterial strains (including enterotoxin production in S. aureus) relies on density dependent cell-cell signaling (QS) molecule, which in turn is the potential target of plant extracts. Thus, inclusion of the above bacterial and fungal strains is rational and justifiable.

\section{Determination of antimicrobial activities}

Agar diffusion method was used to evaluate antimicrobial activities of the extracts according to Tambekar et al [29]. Briefly, $100 \mu \mathrm{l}$ volume of an overnight culture of the reference strains were separately spread over the agar plates (MHA for bacterial strains and PDA for Candida albicans). Sterilized standard paper discs (6 $\mathrm{mm}$ diameter) were placed on the already inoculated culture plates and flooded with $10 \mu \mathrm{L}$ volume of the extracts (aqueous, chloroform, petroleum ether, and methanol; conc. $500 \mathrm{mg} / \mathrm{mL}$ ). Gentamycin sulfate (conc. $1 \mu \mathrm{g} / \mathrm{mL}$ ) and Nystatin (conc. $1 \mu \mathrm{g} /$ $\mathrm{mL}$ ) were used as positive controls for bacterial cultures and Candida albicans, respectively. Antibacterial/antifungal activities of the plant extracts against the test strains were determined after incubation of the test plates for $24 \mathrm{~h}$ at $37{ }^{\circ} \mathrm{C}$ (bacterial strains) or $48 \mathrm{~h}$ at room temperature (for Candida albicans) by measuring the diameter of zone of growth inhibition (IZ). The antimicrobial activity screening was conducted in triplicate experiments and results were an average (mean $\pm \mathrm{SD}$ ) values. A total of 18 plant extracts were analyzed (Table 1). 
Table 1 Summary of traditional medicinal plants and their extracts evaluated for antimicrobial and Quorum Quenching (anti-Quorum Sensing) activities

\begin{tabular}{clll}
\hline Sample No & Code & Scientific name of plant with brief description & Type of Extract \\
\hline 1 & ACFA1 & Aframomum corrorima mature semi-ripe fruit acetone extract & Oleo resin \\
2 & ACFA2 & Aframomum corrorima mature unripe fruit acetone extract & Oleo resin \\
3 & ACFA3 & Aframomum corrorima mature ripe fruit acetone extract & Essential oil \\
4 & ACFO & Aframomum corrorima mature unripe fruit oil & Essential oil \\
5 & ACHO & Aframomum corrorima mature ripe fruit husk oil & Crude extract \\
6 & ASRM & Albiza schimperiana root methanol extract & Oleo resin \\
7 & CLRA1 & Curcuma longa finger rhizome acetone extract & Essential oil \\
8 & CLRO1 & Curcuma longa finger rhizome oil & Essential oil \\
9 & CLRO2 & Curcuma longa main rhizome oil & Oleo resin \\
10 & CLRA2 & Curcuma longa main rhizome acetone extract & Crude extract \\
11 & EBBP & Erythrinia brucei stem bark petroleum ether extract & Crude extract \\
12 & JSSP & Justica schimperiana seed petroleum ether extract & Essential oil \\
13 & NSSO & Nigella sativa seed oil & Crude extract \\
14 & NSSP & Nigella sativa seed petroleum ether extract & Crude extract \\
15 & OSLC & Ocimum sauve leaf chloroform extract & Crude extract \\
16 & VALC & VALM & Vernonia amygdalina leaf chloroform extract \\
17 & VALP & Vernonia amygdalina leaf methanol extract & Crude extract \\
18 & & Vernonia amygdalina leaf petroleum ether extract & Crude extract \\
\hline
\end{tabular}

\section{MIC determination}

The Minimum Inhibitor Concentration (MIC) was determined for those extracts that displayed potent antimicrobial activity against the test strains (activity guided). The standard 96 well micro-titer plate method as described earlier [30] was used with minor modifications to determine the lowest concentration of the extract that inhibit growth of the test strains (the presence or absence of growth was determined through measurement of difference in optical density before and after incubation instead of relying on color change). Accordingly, the initial stock concentration of the extract $(25 \mathrm{mg} / \mathrm{mL})$ was serially diluted in steps of $1: 2$ dilutions $(25,12.5,6.25,3.12,1.5$, $0.5,0.25,0.12 \mathrm{mg} / \mathrm{mL}$ ) by transferring $100 \mu \mathrm{L}$ of the stock extract into wells of micro-titer plate loaded with $100 \mu \mathrm{l}$ nutrient broth, discarding the last $100 \mu \mathrm{l}$ in the dilution series. Overnight cultures of the test strains $(100 \mu \mathrm{l})$ were separately inoculated into the serially diluted extracts except for the culture free control, in a total volume of $200 \mu \mathrm{l}$. Absorbance was measured (at $530 \mathrm{~nm}$ and $340 \mathrm{~nm}$ for bacterial strains and C. albicans, respectively) before incubation for $24-48 \mathrm{~h}$ at $30-32{ }^{\circ} \mathrm{C}$ (for bacteria) and $48 \mathrm{~h}$ (for C. albicans) using ELISA Microplate Reader (SpectraMax Plus 384 Microplate Reader, Molecular Devices, USA). Absorbance was re-measured at the end of incubation to determine the final absorbance and compared with the initial measurement. Non-inoculated wells (wells loaded only with nutrient broth and DMSO, the solvent used to dissolve extracts) were used as negative control while wells with Gentamycin sulfate (conc. $1 \mu \mathrm{g} / \mathrm{mL}$ ) and Nystatin (conc. $1 \mu \mathrm{g} / \mathrm{mL}$ ) were considered as positive controls. The MIC assays were carried out in duplicates.

\section{Quorum quenching assay}

The recently established E. coli reporter strain AI1-QQ.1 was used to detect novel bio-molecules interfering with acyl homoserine lactone (AHL) based bacterial cell-cell communication in the plant extracts [11]. The E. coli reporter comprises a gene encoding a lethal protein fused to promoter induced in the presence of Quorum Sensing signal molecule AHL. Consequently, the E. coli strain is unable to grow in the presence of AHL signal molecules; unless a non-toxic QS-interfering compound is present. Accordingly, Quorum Quenching (QQ) screening plates were prepared as follows: LB top agar containing $0.8 \%$ agar at $50{ }^{\circ} \mathrm{C}$ was supplemented with final concentrations of $100 \mu \mathrm{MN}$-(ß-ketocaproyl)-L-homoserine lactone (3-oxo-C6-HSL) (Sigma-Aldrich, Munich, Germany), $100 \mu \mathrm{g} / \mathrm{mL}$ ampicillin, $30 \mu \mathrm{g} / \mathrm{mL}$ kanamycin, and $10 \%$ (v/ v) exponentially growing culture of the reporter strain AI1-QQ.1. LB agar plates were coated with the top agar mixture. After $10 \mathrm{~min}, 5 \mu \mathrm{L}$ of the plant extracts serially diluted in DMSO $(25,12.5,6.25,3.12,1.5,0.5,0.25$, $0.12 \mathrm{mg} / \mathrm{mL}$ ) were applied, followed by a $1 \mathrm{~h}$ incubation at room temperature (RT) and overnight incubation at $37^{\circ}$ C. QQ activities were visualized by growth of the reporter strain [11]. 


\section{Data analysis}

Data on antimicrobial activities and MIC were analyzed using SPSS software. All antimicrobial activities of plant extracts were compared with the standard antimicrobial agents. The mean inhibition capacity of plant extracts extracted using different solvents were compared using Oneway ANOVA. Descriptive statistics were used to describe the Quorum Quenching activities of the candidate extracts.

\section{Results}

\section{Screening for antimicrobial activity}

The degree of inhibition, as determined by values of diameter of inhibition zone (IZ) of respective extracts, varied among the extracts with the highest inhibition being recorded for petroleum ether extract of seed of Nigella sativa against Bacillus cereus (IZ, $44 \pm 0.31 \mathrm{~mm}$ ), B. cereus ATCC 10987 (IZ, $40 \pm 2.33 \mathrm{~mm}$ ), oil from mature ripe fruit husk of Aframomum corrorima against Candida albicans ATCC 90028 (IZ, $35 \pm 1.52 \mathrm{~mm}$ ) and mature unripe fruit oil of $A$. corrorima against $S$. aureus (IZ, $25 \pm$ $1.32 \mathrm{~mm}$ ) (Table 2). The activities of oil from husk of $A$. corrorima against $C$. albicans and petroleum ether extract of seed of $N$. sativa against both laboratory isolated and reference strain of $B$. cereus were exceptionally high to the extent of exceeding the activity of control antibiotic (Gentamycin sulfate). Furthermore, oil extract from unripe fruit of $A$. corrorima had activity closer to that of Gentamycin sulfate (IZ, $28 \mathrm{~mm}$ ) with inhibition zone diameter of $25 \pm 1.32 \mathrm{~mm}$ against S. aureus DSM 346 . Pseudomonas aeruginosa was the least responsive to any of the plant extracts from among the tested strains.

\section{MIC determination}

The potency of candidate plant extracts were further evaluated after serial dilution of the original concentrated crude extracts to which the strains responded. Accordingly, MIC values of the extracts ranged between 12.5 to $25 \mathrm{mg} / \mathrm{mL}$ with the lowest MIC value $(12.5 \mathrm{mg} /$ $\mathrm{mL}$ ) recorded for oil from husk of Aframomum corrorima against $P$. aeruginosa (Table 3 ). About $40 \%(4 / 10)$ of the extracts with relatively better antimicrobial activities (closer to or even better than the control antibiotics) had MIC value of $25 \mathrm{mg} / \mathrm{mL}$, while $50 \%$ had MIC greater than $25 \mathrm{mg} / \mathrm{mL}$.

\section{Quorum quenching activities of plant extracts}

A total of 18 plant extracts were screened for Quorum Quenching activities using E. coli reporter strain AI1-QQ.1.

Table 2 Antimicrobial activities of selected plant extracts (500 mg/mL conc.) against test strains

\begin{tabular}{|c|c|c|c|c|c|c|c|}
\hline \multirow[t]{2}{*}{ Sample No. } & \multirow[t]{2}{*}{ Code } & \multicolumn{6}{|c|}{ Inhibition zone diameter (mm) of plant extracts against reference strains } \\
\hline & & $\begin{array}{l}\text { E. coli K12 } \\
\text { DSM } 498\end{array}$ & $\begin{array}{l}\text { S. aureus } \\
\text { DSM } 346\end{array}$ & $\begin{array}{l}\text { B. cereus } \\
\text { ATCC } 10987\end{array}$ & $\begin{array}{l}\text { B. cereus } \\
\text { Lab strain }\end{array}$ & $\begin{array}{l}\text { P. aeruginosa } \\
\text { DSM } 1117\end{array}$ & $\begin{array}{l}\text { C. albicans } \\
\text { ATCC } 90028\end{array}$ \\
\hline 1 & ACFA1 & NA & $10 \pm 0.15$ & $12 \pm 1.5$ & $23 \pm 1.8$ & NA & $15 \pm 1.8$ \\
\hline 2 & ACFA2 & NA & NA & $13 \pm 1.08$ & $15 \pm 1.09$ & NA & $12 \pm 2.02$ \\
\hline 3 & ACFA3 & NA & NA & $15 \pm 1.32$ & $13 \pm 1.25$ & NA & $10 \pm 0.76$ \\
\hline 4 & ACFO & $20 \pm 2.01$ & $25 \pm 1.32$ & NA & NA & $12 \pm 1.09$ & NA \\
\hline 5 & $\mathrm{ACHO}$ & $15 \pm 1.71$ & NA & NA & NA & $8 \pm 0.88$ & $35 \pm 1.52$ \\
\hline 6 & ASRM & $12 \pm 1.33$ & $20 \pm 1.04$ & $15 \pm 1.73$ & $18 \pm 1.82$ & NA & NA \\
\hline 7 & CLRA1 & NA & NA & $10 \pm 0.45$ & $9 \pm 1.73$ & NA & NA \\
\hline 8 & CLRO1 & NA & $20 \pm 1.89$ & NA & NA & NA & NA \\
\hline 9 & CLRO2 & $15 \pm 1.56$ & $20 \pm 0.24$ & NA & NA & $10 \pm 1.09$ & NA \\
\hline 10 & CLRA2 & NA & NA & $10 \pm 0.59$ & $12 \pm 1.89$ & NA & $8 \pm 1.32$ \\
\hline 11 & EBBP & NA & $10 \pm 1.33$ & NA & $20 \pm 1.22$ & NA & NA \\
\hline 12 & JSSP & NA & $15 \pm 2.06$ & NA & $20 \pm 0.96$ & NA & $9 \pm 0.86$ \\
\hline 13 & NSSO & $10 \pm 0.98$ & NA & NA & NA & $8 \pm 0.06$ & $20 \pm 2.18$ \\
\hline 14 & NSSP & NA & NA & $40 \pm 2.33$ & $44 \pm 0.31$ & NA & $16 \pm 0.58$ \\
\hline 15 & OSLC & NA & NA & $12 \pm 1.14$ & NA & NA & NA \\
\hline 16 & VALC & NA & NA & $22 \pm 2.11$ & $22 \pm 1.78$ & NA & NA \\
\hline 17 & VALM & NA & NA & $14 \pm 0.99$ & $15 \pm 2.11$ & NA & NA \\
\hline 18 & VALP & NA & NA & NA & NA & NA & $15 \pm 1.24$ \\
\hline 19 & $\begin{array}{l}\text { Gentamycin } \\
\text { Sulfate }(1 \mu \mathrm{g} / \mathrm{mL})\end{array}$ & $25 \pm 0.012$ & $28 \pm 0.03$ & $30 \pm 1.18$ & $25 \pm 0.96$ & $30 \pm 1.05$ & ND \\
\hline 20 & Nystatin (1 ㅆg/mL) & ND & ND & ND & ND & ND & $27 \pm 2.33$ \\
\hline
\end{tabular}


Table 3 MIC of extracts of selected traditional medicinal plants of Ethiopia

\begin{tabular}{|c|c|c|c|c|c|c|c|c|}
\hline \multirow[b]{2}{*}{ Extract/Test strain combinations } & \multicolumn{8}{|c|}{ Concentration of extract (mg/mL) } \\
\hline & 25 & 12.5 & 6.25 & 3.12 & 1.5 & 0.5 & 0.125 & $\mathrm{MIC}(\mathrm{mg} / \mathrm{mL})$ \\
\hline ACFO / S. aureusDSM 346 & + & + & + & + & + & + & + & $>25$ \\
\hline ACFO /E. coli K12 DSM 498 & + & + & + & + & + & + & + & $>25$ \\
\hline ACFO /P. aeruginosa DSM 1117 & - & + & + & + & + & + & + & 251 \\
\hline ACHO/ E. coli K12 DSM 498 & - & + & + & + & + & + & + & 25 \\
\hline ACHO/P. aeruginosa DSM 1117 & - & - & + & + & + & + & + & $12.5 \mid$ \\
\hline CLRO1 / E. coli K12 DSM 498 & + & + & + & + & + & + & + & $>25$ \\
\hline CLRO2 /E. coli K12 DSM 498 & + & + & + & + & + & + & + & $>25$ \\
\hline CLRO2 /S. aureus DSM 346 & - & + & + & + & + & + & + & 25 \\
\hline CLRO2/P. aeruginosa DSM 1117 & - & + & + & + & + & + & + & 25 \\
\hline DMSO + Nutrient broth & + & + & + & + & + & + & + & Control \\
\hline
\end{tabular}

Where: $+=$ growth, - = No growth; for abbreviation of codes, refer to Table 1

Two of the plant extracts, namely Methanol extract of root of Albiza schimperiana (ASRM) and petroleum ether extract of seed of Justica schimperiana (JSSP), displayed observable QQ activities, suggesting the presence of nontoxic AHL interfering molecules in the extracts (Table 4). In addition to QQ activity, Albiza schimperiana had inhibitor activity against some test strains including E. coli K12 DSM 498 (Table 2, Table 4). Twelve of the extracts lack both inhibitory as well as QQ activity at concentrations assessed in the current study.

\section{Discussion}

The emergence of drug resistant pathogens is making the treatment and control of infectious diseases more difficult. Among the common drug resistant pathogens are MultiDrug Resistant TB (MDR TB), Methicillin-Resistant Staphylococcus aureus (MRSA), and Vancomycin-Resistant Enterococci (VRE). In 2013 alone, there were about 480 000 new cases of MDR-TB while extensively drug-resistant tuberculosis (XDR-TB) has been identified in 100 countries [31]. Because of poor performance, in accessibility, and high cost of the available drugs, traditional medicinal plants are getting public acceptance for the treatment of many infectious diseases.

Traditional medicinal plants have long history of application as alternative medicine. In the current study, extracts of different medicinal plants including leaf of Vernonia amygdalina, seed of Nigella sativa, and fruit of Aframomum corrorima displayed promising antimicrobial activity against medically important microbial strains with the highest inhibition zone diameter being recorded against $S$. aureus DSM 346 (IZ, 25 mm), B. cereus ATCC 11987 (IZ, $40 \mathrm{~mm}$ ), laboratory isolated $B$. cereus (IZ, $23 \mathrm{~mm}$ ), and Candida albicans (IZ $35 \mathrm{~mm}$ ). Many of the observed antimicrobial activities were equal or even better than the activities recorded for control antibiotics. Our findings are in agreement with earlier reports on antimicrobial activities of extracts of $A$. corrorima [32], $N$. sativa [22], Aframomum angustifolium [33] and Vernonia amygdalina [34] where the antimicrobial activities were accounted, respectively, to the presence of phenolic compounds [32], phenol, tannin, saponnin and flavonoids [20], flavonoids and terpenoids

Table 4 Quorum Quenching activities of selected medicinal plants of Ethiopia

\begin{tabular}{|c|c|c|}
\hline Extracts & $\begin{array}{l}\text { AHL-QQ activity in } \\
\text { E. coli based reporter } \\
\text { strain Al1-QQ.1 }\end{array}$ & $\begin{array}{l}\text { Antimicrobial activity } \\
\text { against } E \text {. coli } \\
\text { K12 DSM } 498\end{array}$ \\
\hline$\overline{A C F A 1}$ & - & - \\
\hline ACFA2 & - & - \\
\hline ACFA3 & - & - \\
\hline ACFO & - & +++ \\
\hline $\mathrm{ACHO}$ & - & + \\
\hline ASRM & + & + \\
\hline CLRA1 & - & - \\
\hline CLRA2 & - & - \\
\hline CLRO1 & - & - \\
\hline CLRO2 & - & ++ \\
\hline EBBP & - & - \\
\hline JSSP & + & - \\
\hline NSSO & - & + \\
\hline NSSP & - & - \\
\hline OSLC & - & - \\
\hline VALC & - & - \\
\hline VALM & - & - \\
\hline VALP & - & - \\
\hline
\end{tabular}

Where, AHL Acyl homoserine lactone, QQ Quorum Quenching, Al Auto-inducer $+=$ presence of $\mathrm{QQ}$ activity (as observed in reporter strain) or antimicrobial activity (as observed in standard reference strains); - = no activity; For abbreviation of codes, refer to Table 1 
[33], and combinations of some of the above phytochemical compounds including tannins, cardiac glycosides, saponnin and alkaloids [34].

Flavonoids are found in almost all parts of plant $[35,36]$ imparting color to flowers and fruits, and may protect the plant from insect pests and Ultraviolet radiations. Besides their antioxidant, anti-depressant and anti-inflammatory role in the human body, flavonoids act as bactericidal and bacteriostatic by damaging cytoplasmic membrane, inhibiting energy metabolism and synthesis of nucleic acids against different microorganisms [for review, refer to 35]. Flavonoids, including Quercetin, were reported to have antibacterial activity against $S$. aureus, Bacillus subtilis, $B$. cereus, E. coli, Helicobacter pylori, Pseudomonas aeruginosa, P. fluorescens, and Enterobacter aerogenes [35]. Flavonoid chalcone can be used as therapeutic agents against infections of Methicillin-resistant $S$. aureus strains [37]. The other common phytochemical isolated from traditional medicinal plants, is tannin. Tannins inhibit plasma coagulation by S. aureus [38]. It also form chelate with metal ions, and the possible antimicrobial mechanisms of tannins could be: induction of complexation with enzymes or substrates, act on the membranes of microorganisms; and toxicity due to complexation with metal ions [38].

In the current study, Albizia schimperiana displayed moderate activity against most of the test strains in agreement with it reported activities against bacterial (including methicillin-resistant S. aureus and E. coli) and fungal pathogens (Aspergillus fumigatus) [39]. The antimicrobial activities were assumed to be due to the presence of bioactive macrocyclic spermine alkaloid [39].

Although most of the evaluated plant extracts exhibited activities against the test strains, the lowest MIC recorded for fruit husk oil of $A$. corrorima against $P$. aeruginosa $(12.5 \mathrm{mg} / \mathrm{mL})$ was relatively lower than the MIC reported for ethanolic extract of $V$. amygdalina (25 $\mathrm{mg} / \mathrm{mL}$ ) against $P$. aeruginosa [38] but higher than the $<4 \mathrm{mg} / \mathrm{mL}$ value recorded for 36 medicinal plant species evaluated in Peru [40]. The overall MIC values recorded in the present study fall within the wider MIC range $(0.008$ to $256 \mathrm{mg} / \mathrm{mL})$ reported for many of the 141 medical plants of Peru [40] although none displayed strong activity with MIC value $<12.5 \mathrm{mg} / \mathrm{mL}$.

In addition to antimicrobial activities, extracts from traditional medicinal plants could interfere with bacterial cell-cell communication. In the current study, two of the eighteen plant extracts $(11 \%)$ were found interfering with bacterial QS. Likewise, Allison et al. [41] reported $12 \%$ (6/ 50) isolation rate of medicinal plant that exhibit antiQuorum Sensing activities as evaluated using the two biosensor strains, Chromobacterium violaceum and Agrobacterium tumefaciens. In a complex ecosystem where plant, soil microorganisms and abiotic factors are in a constant interaction, constitutive production of signaling molecules among bacterial population and anti-Quorum Sensing molecules by a plant against potentially pathogenic microbes is a natural phenomenon [42]. The behavior of a natural multi-species community is likely to depend at least in part on co-existing QS and Quorum Quenching (QQ) activities [42]. Like all other plants, medicinal plants could also produce signaling molecules and possibly rely on QS and Quorum Quenching (QQ) activities while interacting with the biotic components the ecosystem making them candidate sources of QQ substances in the fight against microbial pathogens.

Generally, biological compounds usually target the bacterial AHL-QS system via three different ways: stops the signaling molecules from being synthesized by the luxI encoded AHL synthase, degrades or modify the signaling molecules and/or target the LuxR signal receptor $[9,43]$. In our case, the plant extracts most likely interfered with AHL signal molecules either through degradation or modification by proteins, or by antagonizing activities of small molecule in the extract (such as 3-oxo-C6-AHL). For wise use of the current finding, the detailed mechanism of action(s) of Quorum Quenching substance(s) need to be determined (one of the limitations of this study). While bacteria use Quorum Sensing communication circuits to regulate a diverse array of physiological activities [44-47], Quorum Quenching prevents the correct operation of Quorum Sensing. The finding that plants have developed Quorum Quenching mechanisms indicates that the plant developed strategies to protect itself against pathogens. Accordingly, the Quorum Quenching activities observed in the current study could mainly be accounted to the presence of autoinducers (AHL) inhibitors in our plant extracts.

Based on the current findings and many of the earlier observations, traditional medicinal plants will continue to be the source of alternative antimicrobial substances to combat the challenges being confronted due to emergence of drug resistant microbes. Series of reports confirmed the high prevalence of drug resistant bacterial strains in both clinical and food samples [22, 48-50]. Increased prevalence of drug resistant bacteria, together with lack and/or high costs of new generation drugs have been escalating infection-related morbidity and mortality particularly in developing countries like Ethiopia [24]. Thus, detection of plants with potent activity against pathogenic microorganisms in the current study as supported by earlier reports from Ethiopia [17, 19-22] further strengthen the feasibility of looking for an alternative approach to manage drug resistant microbes. As stressed by many scholars, using effective plant extracts to control human diseases has the additional advantage of low production costs, minimal environmental damage and higher accessibility to rural communities $[23,51]$. 


\section{Conclusion}

Based on the current finding and the available literature, it could be concluded that medicinal plants have significant role in human medication, displaying both antimicrobial and anti-Quorum Sensing activities. The latter case is safer as it will not kill bacteria and the likely chance of development of resistance is low, if any. The fact that the petroleum ether extract of $N$. sativa displayed even better activity against $B$. cereus strains as compared to the commercial control antibiotic, Gentamycin sulphate, reveals the future prospects of traditional medicinal plants of Ethiopia in the treatment of many diseases and will be source of many biochemical molecules of therapeutic importance.

Furthermore, the anti-QS activities observed among two of the Ethiopian traditional medicinal plants is good indication of potential application of plant extracts for the regulation of microbial physiology in the way it fits human interest. Thus, Quorum Quenching could be an alternative strategy to combat bacterial infections as it lowers the development of multidrug resistant pathogens. In addition, as plants are constantly exposed to bacterial infections, similar to humans and other animals, it is logical to expect that plants have developed sophisticated chemical mechanisms to inhibit biofilm formation and other microbial pathogenesis. Being the first assessment of its kind on the potential application of Ethiopian traditional medicinal plants for interference in microbial cell-cell communication (anti-Quorum Sensing activities), the detailed chemistry of the active compounds and possible mechanism(s) of actions of the bio-molecules responsible for the observed interference were not addressed in the current study. Thus, further evaluation for the nature of those active compounds (biomolecules) and detailed mechanism(s) of their interaction with microbial processes are recommended

\section{Abbreviations \\ AHL, acyl homoserine lactone; Al, auto-inducer; ATCC, American type culture collection; DMSO, dimethyl sulfoxide; DSM, Deutsche sammlung von mikroorganismen (German Collection of Microorganisms and Cell Cultures); IZ, inhibition zone; MDR TB, multi-drug resistant TB; MHA, Muller Hinton Agar; MIC, minimum inhibitory concentration; MRSA, methicillin-resistant Staphylococcus aureus; PDA, potato dextrose agar; $\mathrm{QQ}$, quorum quenching; QS, quorum sensing; VRE, vancomycin resistant enterococci; XDR-TB, extensively drug-resistant TB}

\section{Acknowledgments}

The authors would like to thank the traditional healers in the study area for provision of information about the medicinal plants and traditional practices.

\section{Funding}

The authors would like to thank Jimma University and TWAS-DFG for financial support to KB through TWAS-DFG Research Visit scheme.

\section{Availability of data and materials}

The datasets supporting the conclusions of this article are included within the manuscript.

\section{Authors' contributions}

$K B, Y T$ and RAS were involved in the designing of this research, data collection and supervision. MM, FG and SZ were involved in the preliminary study, plant collection, processing and extraction. NW performed
QQ assays. AM and YT supervised the plant collection and extraction processes. KB further prepared the manuscript for publication while NW, $A M$ and RAS reviewed the manuscript. All authors read and approved the final version of the manuscript.

\section{Competing interest}

The authors declare that they have no competing interests.

\section{Consent for publication}

Not applicable.

\section{Ethics approval and consent to participate}

Not applicable.

\section{Author details}

${ }^{1}$ Depatment of Biology, College of Natural Sciences, Jimma University, Jimma, Ethiopia. ${ }^{2}$ Department of Chemistry, College of Natural Sciences, Jimma University, Jimma, Ethiopia. ${ }^{3}$ Department of Horticulture, College of Agriculture, Adigrat University, Adigrat, Ethiopia. ${ }^{4}$ Department of Horticulture and Plant Science, College of Agriculture and Natural Resources Management, Gambella University, Gambella, Ethiopia. ${ }^{5}$ Departemnt of Postharvest Management, College of Agriculture and Veterinary Medicine, Jimma University, Jimma, Ethiopia. ${ }^{6}$ Institut für Allgemeine Mikrobiologie, Christian-Albrechts-Universität zu Kiel, Kiel, Germany. ${ }^{7}$ Derpartment of Biology, College of Natural and Computational Sciences, Wollo University, Dessie, Ethiopia.

Received: 3 February 2016 Accepted: 7 July 2016

Published online: 11 July 2016

\section{References}

1. Arunkumar S, Muthuselvam M. Analysis of Phytochemical Constituents and Antimicrobial Activities of Aloe vera L. against Clinical Pathogens. World J Agri Sci. 2009;5:572-6.

2. Koshy P, Wirakarnain S, Sim KS, Saravana K, Hong SL, Lee GS, Syarifah N, and Rahman SA. Antimicrobial Activity of Some Medicinal Plants from Malaysia. American J Appl Sci. 2009:6:1613-7.

3. Edwards S. The ecology and conservation status of medicinal plants of Ethiopia. What do we know? In: Medhin Z, Abebe D, editors. Conservation and Sustainable use of medicinal plants in Ethiopia, Proceeding of National Workshop on Biodiversity Conservation and Sustainable use of medicinal plants in Ethiopia. Addis Ababa: Institute of Biodiversity Conservation and Research; 2001.

4. Bekele E. Study on Actual Situation of Medicinal Plants in Ethiopia. Addis Ababa: Prepared for Japan Association for International Collaboration of Agriculture and Forestry; 2007.

5. Gidey Y. Assessment of indigenous knowledge of medicinal plants in Central Zone of Tigray, Northern Ethiopia. African J Plant Sci. 2009:4:006-11.

6. Parekh J, Chanda SV. In vitro Antimicrobial Activity and Phytochemical Analysis of Some Indian Medicinal Plants. Turk J Biol. 2007;31:53-8.

7. Jay JM, Loessner MJ, Golden DA. Modern Food Microbiology. 7th ed. New York: Springer Science + Business Media Inc; 2005.

8. Todar K. Mechanisms of Bacterial Pathogenicity. Todar's Online Book of Bacteriology. http://textbookofbacteriology.net/pathogenesis.html, 2016. Accessed on Mar 2016

9. Koh C-L, Choon-Kook Sam, Wai-Fong Yin, Li Ying Tan, Thiba Krishnan, Yee Meng Chong and Kok-Gan Chan. Plant-Derived Natural Products as Sources of Anti-Quorum Sensing Compounds. Sensors. 2013;13:6217-28. doi:10.3390/s130506217.

10. Li Y-H, Tian X. Quorum Sensing and Bacterial Social Interactions in Biofilms. Sensors. 2012;12:2519-38. doi:10.3390/s120302519.

11. Weiland-Bräuer N, Pinnow N, Schmitz RA. Novel reporter for identification of interference with acyl homoserine lactone and autoinducer-2 quorum sensing. Appl Environ Microbiol. 2015;81:1477-89. doi:10.1128/AEM.03290-14.

12. Blackwell HE, Fuqua C. Introduction to bacterial signals and chemical communication. Chem Rev. 2011;111:1-3. http://pubs.acs.org/doi/pdfplus/10. 1021/cr100407j.

13. González JE, Keshavan ND. Messing with bacterial quorum sensing Microbiol MolBiol Rev. 2006;70:859-75. 
14. Kjelleberg S, Steinberg P, Givskov M, Gram L, Manefield M, DeNys R. Do marine natural products interfere with prokaryotic $\mathrm{AHL}$ regulatory systems? Aquat Microbial Ecol. 1997;13:85-93.

15. Simanski M, Babucke S, Eberl L, Harder J. Paraoxonase 2 acts as a quorum sensing-quenching factor in human keratinocytes. J Invest Dermatol. 2012; 132:2296-9.

16. Chun CK, Ozer EA, Welsh MJ, Zabner J, Greenberg EP. Inactivation of a Pseudomonas aeruginosa quorum-sensing signal by human airway epithelia. Proc Natl Acad Sci U S A. 2004;101:3587-90.

17. Geyid A, Abebe D, Debella A, Makonnen Z, Aberra F, Teka F. Screening of some medicinal plants of Ethiopia for their anti-microbial properties and chemical profiles. J Ethnopharmacol. 2005;97:421-7.

18. Tadeg H, Mohammed E, Asres K, Gebre-Mariam T. Antimicrobial activities of some selected traditional Ethiopian medicinal plants used in the treatment of skin disorders. J Ethnopharmacol. 2005:100:168-75.

19. Taye B, Giday M, Animut A, Seid J. Antibacterial activities of selected medicinal plants in traditional treatment of human wounds in Ethiopia. Asian Pac J Trop Biomed. 2011;1(5):370-5.

20. Lulekal E, Rondevaldova J, Bernaskova E, Cepkova J, Asfaw Z, Kelbessa E. Antimicrobial activity of traditional medicinal plants from Ankober District, North Shewa Zone, Amhara Region, Ethiopia. Pharm Biol. 2014;52(5):614-20.

21. Wasihun Y, Adraro T, Ali S. Evaluation of antibacterial activity and phytochemical constituents of leaf extract of Lippia adoensis. Asia Pacific J Energy Environ. 2014;1(1):45-53.

22. Mulat M, Chali K, Tariku Y, Bacha K. Evaluation for in-vitro antibacterial activity of selected medicinal plants against food-borne pathogens. In J Pharmaceutical Sci Rev Res. 2015;32(2):45-50.

23. Teka A, Rondevaldova J, Asfaw Z, Demissew S, Patrick Van Damme P, Kokoska $L$, and WouterVanhove W. In vitro antimicrobial activity of plants used in traditional medicine in Gurage and Silti Zones, south central Ethiopia. BMC Complement Altern Med. 2015;5:286. doi:10.1186/s12906-015-0822-1.

24. Chen H, Fujita M, Feng Q, Clardy J, Fink GR. Tyrosol is a quorum-sensing molecule in Candida albicans. Proc Natl Acad Sci U S A. 2004;101:5048-52.

25. Hornby JM, Jensen EC, Lisec AD, Tasto JJ, Jahnke B. Quorum sensing in the dimorphic fungus Candida albicans is mediated by farnesol. Appl Environ Microbiol. 2001;67:2982-92.

26. Madhani HD. Quorum sensing in Fungi. PLoS Pathog. 2011;7(10):e1002301 doi:10.1371/journal.ppat.1002301.

27. Panthi MP, Chaudhary RP. Antibacterial activity of some selected folklore medicinal plants from West Nepal. Scientific World. 2006:4:205-10.

28. Handa SS, Khanuja SP, Longo SG, Rakesh DD, editors. Extraction Technologies for Medicinal and Aromatic Plants. Trieste: International Centre for Science and High Technology; 2008.

29. Tambekar DH, Khante BS, Panzade BK, Dahikar SB, Banginwar YS. Evaluation of Phytochemical and Antibacterial Potential of Helicteres isora L. Fruits against Enteric Bacterial Pathogens. Afr J Tradit Complement Altern Med. 2008;5:290-3.

30. Buwa LV, van Staden J. Antibacterial and antifungal activity of traditional medicinal plants used against venereal diseases in South Africa. J Ethnopharmacol. 2006;103(1):139-42.

31. WHO REPORT. Antimicrobial resistance, Fact sheet No.194. http://www.who. int/ mediacentre /factsheets/fs194/en/), 2015, Accessed on 20 Jan 2016.

32. Eyob S, Martinsen BK, Tsegaye A, Appelgren M, Skrede G. Antioxidant and antimicrobial activities of extract and essential oil of korarima (Aframomum corrorima (Braun) P.C.M. Afr J Biotech. 2008;7:2585-92.

33. Godwin UA, Claude K. Phytochemical profile and antibacterial activity of crude extracts of the pod of Aframomum angustifolium (Sonn.) K. Schum. European Journal of Biological Research. 2015;5(2):36-41.

34. Adetunji CO, Olaniyi OO, Ogunkunle ATJ. Antibacterial activity of crude extracts of Vernonia amygdalina on clinical isolates. J Microbiol Antimicrobial. 2013;5(6):60-4

35. Ahmed A, Kaleem M, Ahmed Z, Shafiq H. Therapeutic potential of flavonoids and their mechanism of action against microbial and viral infections-A review. Food Res Inter. 2015;77:221-35.

36. Cushnine T, Lamb AJ. Antimicrobial activity of flavonoids. Inter J Antimicrobial Agents. 2005;26(5):343-56.

37. Alcaraz L, Blanco S, Puig O, Tomas F, Ferretti F. Antibacterial activity of flavonoids against methicillin-resistant Staphylococcus aureus strains. J Theor Biol. 2000;205(2):231-40.

38. Akiyama H, Fujii K, Yamasaki O, Oono T, Iwatsuki K. Antibacterial action of several tannins against Staphylococcus aureus. J Antimicrobial Chemotherapy. 2001;48(4):487-91.
39. Samoylenko V, Jacob MR, Khan SI, Zhao J, Tekwani BL, Midiwo, Walker LA, Muhammad I. Antimicrobial, antiparasitic and cytotoxic spermine alkaloids from Albizia schimperiana. Nat Prod Commun. 2009;4(6):791-6.

40. Bussmann RW, Malca-Garcia G, Glenn A, Sharon D, Chait G, Diaz D, Pourmand K, Jonat B, Somogy S, Guardado G, Aguirre C. Chan R, Meyer K, Kuhlman A, Townesmith A, Effio-Carbajal J, Frías-Fernandez F and Benito M. Minimum inhibitory concentrations of medicinal plants used in Northern Peru as antibacterial remedies. J Ethnopharmacol. 2010;132(1):101-8.

41. Allison A, Kong KF, Mathee K. Inhibition of quorum sensing-controlled virulence factor production in Pseudomonas aeruginosa by South Florida plant extracts. Antimicrob Agents Chemother. 2008:52:198-203.

42. Adonizio AL, Downum K, Bennett BC, Mathee K. Anti-quorum sensing activity of medicinal plants in southern Florida. J Ethnopharmacol. 2006;105:427-35.

43. Chan KG, Atkinson S, Mathee K, Sam CK, Chhabra SR, Cámara M, et al. Characterization of $\mathrm{N}$-acylhomoserine lactone-degrading bacteria asso-ciated with Zingiber officinale (ginger) rhizosphere: Co-existence of quorum quenching and Quorum Sensing in Acinetobacter and Burkholderia. BMC Microbiol. 2011;11:51.

44. Miller MB, Basler BL. Quorum sensing in bacteria. Annu Rev Microbiol. 2001:55:165-99.

45. Schauder S, Bassler BL. The languages of bacteria. Gene Develop. 2001:15:1468-80.

46. Cvitkovitch DG, Li Y-H, Ellen RP. Quorum Sensing and biofilm formation in streptococcal infections. J Clinical investigations. 2003:112(1):1626-32.

47. Ryan RP, Dow JM. Diffusible signals and interspecies communication in bacteria. Microbiology. 2008:154:1845-58.

48. Dabassa A, Bacha K. The Prevalence and antibiogram of Salmonella and Shigella Isolated from abattoir, Jimma town, South West Ethiopia. Int J Pharmaceutical and Biological Res. 2012;3(4):143.

49. Dugassa A, Ketema T, Bacha K. Microbiological quality and safety of some selected vegetables sold in Jimma town, Southwestern Ethiopia. Afr J Environ Sci Technol. 2014;8(11):633-53

50. Wolde T, Bacha K. Prevalence and Antibiotics Resistance Patterns of Staphylococcus aureus Isolated from Kitchen Sponge's at Jimma Town Food Estab- lishments, South West Ethiopia. Int J Research Studies in Bioscience. 2015;3(7):63-71

51. Savoia D. Plant-derived antimicrobial compounds: alternatives to antibiotics. Future Microbiol. 2012;7(8):979-90.

\section{Submit your next manuscript to BioMed Central and we will help you at every step:}

- We accept pre-submission inquiries

- Our selector tool helps you to find the most relevant journal

- We provide round the clock customer support

- Convenient online submission

- Thorough peer review

- Inclusion in PubMed and all major indexing services

- Maximum visibility for your research

Submit your manuscript at www.biomedcentral.com/submit 